\begin{tabular}{ccc}
\hline CHTKRA & Journal of Chemistry, Environmental Sciences & and its Applications \\
UNIVERSITY & Journal homepage: https://jce.chitkara.edu.in/ \\
\hline
\end{tabular}

\title{
Accessibility of Water Among Scheduled Castes in Rural Punjab Issues and Challenges
}

\author{
Dr Bindu Duggal \\ Associate Professor, Centre for Research in Rural and Industrial Development. Sector 19-A, 160 019, Chandigarh, India \\ Email: binduduggal@gmail.com
}

\begin{tabular}{l} 
ARTICLE INFORMATION \\
\hline Received: 03 July 2017 \\
Revised: 07 July 2017 \\
Accepted: 25 July 2017 \\
Published Online: September 6, 2017 \\
\hline
\end{tabular}

\begin{abstract}
Access and availability to safe drinking water is not only an important gauge of the socioeconomic status of the household but is also imperative to the health of its members. Efforts have made for high coverage of water in Punjab. In spite of huge progress, the rural water sector still continues to face major challenges. The problem is more acute among Scheduled Castes as only 78 per cent households had drinking water source within the premises in Punjab as per Census 2011. The main objective of the study is to analyses the status and problems of water accessibility among this marginalized section of the society. The present research is based on both Secondary and Primary sources of data collected from SC households in rural Mansa in Punjab. Empirical data was collected through intensive field work using the survey method. Multi-stage sampling technique was adopted. A sample of 200 Scheduled Caste households from 10 villages was selected for the study. The present research unveils that Scheduled castes families face threats to all three prerequisites of an individual's right to water i.e. there is insufficient water availability, lack of access to water and danger due to water quality, making
\end{abstract} DOI: https://doi.org/10.15415/jce.2017.41001 them easy prey to a number of diseases.

\section{Introduction}

Access to safe water is a fundamental human need and, therefore, a basic human right. Contaminated water jeopardizes both the physical and social health of all people. It is an affront to human dignity.

-Kofi Annan, former United Nations Secretary

Potable water and sanitation are explicitly recognised as important rights that are essential for the full enjoyment of life. Going by the principles of the international treaty on the rights of water, water is a fundamental human right and states must be willing and able to implement their respective obligations to respect, protect and fulfil the right to adequate water. In light of the right to water framework, the UN Committee on Economic, Social, and Cultural Rights, states that an individual's right to water includes "sufficient, safe, acceptable, physically accessible and affordable water for personal and domestic issues." Fulfilment of the right to water requires water that is available, safe and accessible. In brief, a person should have enough water for personal and domestic issues (including food preparation, sanitation washing clothes) and this water should be safe.

Water is a basic necessity for the survival of humans. Globally, the world is on track to meet the MDG on safe drinking water. India too is on track with 85.5 per cent population having sustainable access to safe drinking water (Census of India, 2011). Although, there have been improvements and it is felt that India is seriously targeting to achieve its aggregate level Millennium Development Goal for providing access to safe drinking water, yet nearly 130 million people in India still do not have access to clean water. Additionally, there remains a worrying discrepancy in access between urban and rural areas. About 91.4 per cent urban population in comparison to only 82.7 per cent rural population have access to safe drinking water. Meeting the drinking water needs of such a large population can be an intimidating task. Thus, lack of safe drinking water persists to be a major hurdle and a national economic burden.

Further, "About 37.7 million Indians are affected by waterborne diseases, 1.5 million children die of diarrhoea and 73 million working days are lost due to waterborne diseases annually. Further, 10.28 per cent of all habitations being affected by poor water quality. It is estimated that by 2020, India will become a water-stressed nation" (Water Aid India, 2017). Although, water is the most integral and inevitable part of each individual; however discrimination of Scheduled Caste in access to water is often cited. According to the Census of India 2011, only 35 per cent of the Scheduled Caste households had the main source of drinking water within the premises, whereas, a large 65 per 
cent were near or away from the premises. There were only 28 per cent households in rural areas in comparison to 57 per cent in urban areas having main drinking water source within the premises. Further, 41.3 per cent of SC households in our country has tap water from a treated source/untreated sources (29.4\% from treated and $11.9 \%$ from untreated) as the main source of drinking, and the remaining draw water from rivers, canals, ponds, lakes or 'other sources' (not taps, hand pumps, wells, tube wells or boreholes).

Punjab ranks highest among States and UTs with 97.6 per cent households having access to safe drinking water. Safe water here means having taps, tube-well, hand-pumps as the main source for drinking water. The access to safe water supply in rural areas is estimated to be available in 96.7 per cent of the households in comparison to 99 per cent in urban households. In spite of huge progress, water in rural sector still continues to face major challenges. The problem is more acute among Scheduled Caste households. Punjab has the highest percentage of scheduled caste population in the country. There are 88.60 lacs SCs in Punjab which is 31.94 per cent of the total population (277.43 lacs) of the State. Punjab accounts for 2.3 per cent of the total population and 4.3 per cent Scheduled Caste population of India. Regarding the accessibility of water among Scheduled Castes in Punjab, only 78 per cent had drinking water source within the premises as per census 2011.These facts make it pertinent to study the plight of Dalits in Punjab who still face multiple deprivation and discrimination with regard to water facility.

\subsection{Review of Literature}

Soni Jayashree, 2006, in the study of water accessibility in eight villages in Gujarat analyses the practice of untouchability and lack of water accessibility to Dalits adding extra burden on SCs by forcing them to bring water from distant and different places, taking away too much of their time and energy. It also highlights the difficulty and humiliation Dalit women face in the collection of water who therefore desired separate water spots or pumps to evade quarrels. Swaminathan and Singh (2004) based on pooled data from surveys of 12 villages in five states highlighted the inequality faced by Dalits, in terms of access to basic amenities and observed that there is a strong statistical association between caste and access to the basic amenities like sanitation and water. Hannah Johns in his paper on 'Stigmatization of Dalits in Access to Water and Sanitation in India' stresses on issues like power hierarchy in access to water Infrastructure, inaccessibility, violence in access to water and sanitation. Lack of safe drinking water and sanitation triggers a chain reaction, leading to further marginalization of the SCs.
Many studies have brought out caste based discriminations leading to human rights violation regarding drinking water, making it an important social issue. However there is real dearth of research studies conducted on water problems faced by SCs in Punjab, although the highest proportion of this disadvantaged sections reside in Punjab. The present study, therefore, aims to explore these problems faced by the SCs in the state of Punjab. The field reality brought out by the present empirical study can be an eye opener for sensitizing government towards protection of water rights of SCs and setting priorities in the programs and plans for the vulnerable sections.

\subsection{Various Initiatives taken by Government at National and State Level}

There have been various Initiatives taken to improve access to water at the state and national level. In fact, "Water supply and sanitation were added to the national agenda during the country's First Five-Year Plan (1951-56). Government of India's reforms in sanitation along with water supply, thus, started to gain in strength from the middle of 1999 onwards"(A Movement Towards Total Sanitation in India,2006). TSC was renamed as Nirmal Bharat Abhiyan (NBA) in 2012 and was later merged with Mahatma Gandhi National Rural Employment Guarantee Scheme. The Government of Punjab is very much aware of the problems with regard to water and therefore a lot many efforts are being made and the Rural Water Supply Schemes/Projects are primarily being implemented by the department under following programmes: National Rural Drinking water Programme (NRDWP); Punjab Rural water Supply and Sanitation Project (World Bank assisted); Project assisted by NABARD. Despite massive programmes on drinking water as discussed above, it is observed that access to safe drinking water remain a major challenge among SCs. These facts make it pertinent to study the plight of the Scheduled Castes (SCs) in detail and hence a thorough study on Mansa in Punjab state was undertaken.

\section{Objectives of the Study}

The main objective of the present study is to analyse the accessibility of water in Scheduled Caste households; to explore and understand the problems faced by Scheduled Castes in context to lack of water; and to provide suggestions to strengthen their right to safe drinking water.

\section{Methodology}

The present research is based on both Secondary and Primary sources of data collected on SC households in Rural Mansa in Punjab. Primary data was collected through intensive 
field work using the survey method. Punjab has the highest proportion of scheduled caste population (31.94\%) in the country. Mansa was selected for the study as it is one of the most backward districts in Punjab, having very high proportion of SC population (33.63\%). The study was restricted to rural areas as the Scheduled Caste population is predominantly rural by residence. A pretested Questionnaire including both structured and open-ended questions was prepared to collect the empirical data. Multi-stage sampling technique was adopted to select the sample. Village wise information of SC households in Mansa was collected from the Department of water Supply and Sanitation, Punjab (DWSS). The selection procedure further includes two-stage stratified sampling. At the first stage, two villages having very high SC population from each of the five blocks in Mansa, making a total of 10 villages were selected namely Aklian, PhaphreBhaike. Bahaderpur, Kurlian, FattaMaluka, Ubha, Raipur, Behniwal, Nangal Kalan and Sanga. At the second stage, 20 SC households were selected randomly from each of the selected village. Thus, the total sample size included 200 Scheduled Caste households from 10 villages in Mansa.

\section{Results and Discussions Largely Based on Empirical Research}

The following findings reveal the socio-economic and demographic profile and the status of SCs in terms of access to water in rural Mansa of Punjab based largely on the households surveyed.

\subsection{Socio-demographic-Economic Profile of the SC Households}

The empirical data collected through a survey conducted by CRRID on scheduled castes revealed that majority of them were in the age group 31-50 years and the average age of the respondents was 40years.Majority of them $(81 \%)$ were married and lived in nuclear families $(66 \%)$. The average family size of the SC household was 4.91. A large proportion of the SC families (97\%) belonged to Sikh community. Household heads of SC families were largely illiterate (72\%) and were working as labourers and were daily wagers. They were involved as casual labourers in non-agriculture sector (62\%). Regarding women occupation, 64 per cent of the SC women were housewives followed by 16 per cent working as daily wagers/ labourers, 12 per cent as agricultural labourers, four per cent as domestic servant and the remaining were self-employed and running shops etc. However, among the ones reporting themselves as housewives, almost 75 per cent among them were seasonal workers. Majority of the SC families were residing in single room, semi pucca houses. The average family income of the family was Rs. 6,880/-per month, which is quite low in this era of high prices.

\subsection{Access, Availability and Quality of Water}

Fulfilment of the right to water requires water that is available, accessible and safe.

\section{Private Water Connection}

Punjab state is committed to providing100per cent metered household private water connection in all rural areas of the state. However, the reality captured by the empirical data is that only 60 per cent from the total surveyed households had private water connections.

\section{Main Source of Drinking Water}

Table 1 clearly show that the main source of drinking water in Mansa was tap which was reported by 69 per cent households $(65 \%$ depended on tap water available within household or taken from neighbours or relatives and $2 \%$ brought water from water works/Digi etc.). Five per cent households depended on $\mathrm{RO}$ water and 1.5 per cent used water taken directly from canal. 27 per cent of the households depended on ground water as the main source of drinking water $(20 \%$ used submersible/bore well water and $7 \%$ used Hand pumps).

Table 1. Distribution of SC Households according to Main Source of Drinking Water.

Main Source of drinking water

\begin{tabular}{llllllll} 
Village & $\begin{array}{l}\text { Tap water } \\
\text { within HH/ } \\
\text { neighbour/ } \\
\text { Relative }\end{array}$ & RO & $\begin{array}{l}\text { tap water } \\
\text { from water } \\
\text { box /digi }\end{array}$ & Handpump & $\begin{array}{l}\text { Gubmersible/ } \\
\text { Tubewell/ } \\
\text { Borewell }\end{array}$ & $\begin{array}{l}\text { Canal/ } \\
\text { distributary }\end{array}$ & \\
\hline Total & $129(64.5)$ & $9(4.5)$ & $5(2.5)$ & $13(6.5)$ & $41(20.5)$ & $3(1.5)$ & $200(100.0)$ \\
\hline
\end{tabular}

Source: CRRID Field Survey, 2017 


\section{Accessibility to water (Location of Source of Drinking Water)}

Table 2 Distribution of Households According to the Location of Water Source.

\begin{tabular}{lll}
\hline Location & No. of Households & Percent \\
\hline Within premises & 141 & 70.5 \\
Near premises & 45 & 22.5 \\
Away & 14 & 7.0 \\
Total & 200 & 100.0 \\
\hline
\end{tabular}

Source: CRRID Field Survey, 2017

Of the households surveyed, 71 per cent had the main drinking water facility within premises, 22 per cent were fetching water from near the premises and eight per cent had the drinking water source away from premises. Drinking water source could be any i.e. tap, handpump, submersible etc on which the SC family was mainly dependent.

\section{Source of Water for Washing Utensils/Clothes}

Fifty five per cent of the surveyed households used submersible sets, 15 per cent used handpumps and 2 per cent used borewell/ tubewell water for washing/cleaning purposes. In other words, 72per cent used ground water either from their own house or neighbours for washing clothes and cleaning utensils. Only10 per cent households depended on tap water (even if they had to fetch water) for washing/ cleaning purposes. 8 per cent brought water directly from the water works for these mundane needs. 11 per cent went near canals to wash their clothes or carried water directly from there to use it for washing and cleaning. People take bath, wash clothes on the side of the canal/ distributaries. Nearly, three-fourths of the respondents reported that their utensils and clothes do not shine and remain dull i.e. they feel that they are not totally clean even after they are washed thoroughly due to poor quality of water used, but they had no choice.

\section{Availability of Water/Scarcity of Water}

After analysing the source of water, it was of interest to know about the water availability, which is defined as having enough water for personal and domestic issues. The existing water supply scheme in Punjab is designed to provide 70 litres per capita per day potable water. The present Scenario in State of Punjab (RWS sector) reveals that the state has high service coverage for water (95\%).

As per DWSS, Mansa,97 per cent villages are fully covered (having at least 70 litres of piped water per capita per day. The total water supplied per household was 350 litres. The government is giving the water connections free of cost at present. The department blamed the beneficiaries for facing dearth of water as they felt that they wasted a lot of water. They would often leave the taps open. They clarified that water was affordable and that the only bill the SC needs to pay is Rs. 75 per month.

However, during the CRRID field study, number of SC households in a few villages surveyed reported that there were no pipelines or no private water connections and there was inadequacy of water available. Neither all SC households had connections, nor was the norm of supply of 70 lpcd of water fulfilled in their villages. Their villages did not have $24 x 7$ water supply. They remarked that the government had failed to carry out its commitment to satisfy their need of water for drinking and other domestic purposes. Water from water works is not available to people regularly. It is hardly available for 20 days in a month and that too in peak months. Even those getting tap water from water works in routine reported that since water was available for fixed hours and due to low pressure of water, there was perpetual scarcity of water in almost all SC households in all villages. Even in routine people complain that the timings are very limited and they are able to have access to water only for one hour in the morning and half an hour in the evening. Further, it was also highlighted that sometimes when Bhakra Canal dries up or has less water, then tap water is not available at all for many days at a stretch. The respondents having tap connections at home reported that water was very irregular throughout the year. Also the location of SC localities was such that the pressure of water was very low. Further, there was real dearth of water in majority of the months every year but summer months were the worst. Many a times there was a fault in water works, and then SC households had to be without tap water for days and months together. To sum up, nearly 100 per cent of the households surveyed reported that the tap water from water works was not available in their households for the full year and they faced dearth of water for drinking and other domestic purposes. Thus, by and large, in SC Habitation, the quantum of availability of safe water from any source is not enough to meet drinking, cooking and other needs. Thus, although the coverage appears high as per the government data, but it seems that a large number of water supply schemes are serving only a limited population with house connection.

Further, discrimination in distribution of water from water works resulting in shortage of water in SC households was reported during the survey. It was stated that the pressure of water was less in villages. People used different sizes and quality of pipes to draw water. Sarpanch, Panch, Ward members, members, Jats all have better water facility as they used thick 6 inches dia pipe or tullu pumps to pull and divert the pressure of water into their houses. The SCs remained behind as they couldn't afford big pipes or tullu pumps and the houses are mostly located at such locations where the 
pressure of water was very less. Thus, there is always lack of water for one or the other reason in SC households.

\section{Alternate Source of Drinking Water in Emergency}

An effort was made to explore the substitute source of drinking water in emergency/summer/ or when routine water is not available in SC households. The following were the responses:

Table 3. Alternative Source of Drinking Water during Emergency/ Summers/Shortage of water.

\begin{tabular}{lll}
\hline $\begin{array}{l}\text { Alternate Source of } \\
\text { drinking water }\end{array}$ & No. of Households & Percent \\
\hline Tap water & 8 & 4.0 \\
submersible motor & 117 & 58.5 \\
Hand pump & 22 & 11.0 \\
Canal water & 22 & 11.0 \\
$\begin{array}{l}\text { Purchase water from } \\
\text { tanker supply }\end{array}$ & 8 & 4.0 \\
water box digi untreated & 10 & 5.0 \\
tube wall in field & 4 & 2.0 \\
R/O Water & 9 & 4.5 \\
Total & 200 & 100.0 \\
\hline
\end{tabular}

Source: CRRID Field Survey, 2017

Fifty nine per cent of the SC households reported that they depend totally on submersible motor (either their own or neighbours) for drinking purposes during scarcity of water, although, they all knew that water from submersible motor was of very poor quality and totally unfit for consumption. Another 11 per cent were depended on Hand pumps, two per cent consumed tube well water in field, meaning thereby that 72 per cent of the SC households have to largely depend on ground water during emergency. Eleven per cent brought water from canal and its distributaries and five per cent brought water from the water box/digi (untreated), during water crises. Four per cent were forced to purchase water from tankers. Only five per cent were depended on $\mathrm{R} / \mathrm{O}$ Water and the number of households dependent on $\mathrm{RO}$ does not increase in emergency due to great rush at RO Site by Jat families. So, except for a very small proportion who consumes safe water, almost all SC families were forced to consume contaminated/untreated water, not fit for consumption for many days each month during emergency.

Thus, the commitment of the existing water supply schemes designed to provide 70 litres per capita per day potable water has not been achieved, resulting in scarceness of water and forcing the rural SCs to depend on ground water to satisfy their drinking needs.

\section{Distance from where Water is collected}

As already discussed, many people don't have water facilities within the house. In addition, water deficiency is also experienced in routine in most of the houses having access to piped water.Only38 per cent of the respondents don't have to get water every day. They could manage in routine with the water available at home. However, 62 per cent of the households felt the need to fetch water everyday due to water insufficiency because of limited hours of water supply; low pressure or no piped connections at all. Many houses didn't have even submersibles/handpumps. Thus, in majority of the SC households, even if they have or don't have a water source at home, they feel the necessity to fetch water especially for drinking, cooking and other purposes almost every day or every second-third day and especially each day in summers. Majority of the people prefer water from water works for drinking and cooking purposes, so in routine also due to deficiency in water supply within the households, they try to fetch water from here and there. The field survey revealed that 31 per cent had to fetch water from a distance of 100 meters. Another 31 per cent had to get water from 101 to 500 meters and 23 per cent from 501 to 1,000 meters. 15 per cent population had to procure water from a distance of one $\mathrm{Km}$ to two Kms. every day.

\section{Who Procures Water and how?}

In 80 per cent of the SC households, usually the women fetched water. Many a times, children helped them. Women and children faced a tough time as there were long queues near the water source, especially during days when there was real scarcity of water, which many a times resulted in quarrels. A large majority (85\%) amongst those bringing water from outside carried the water and brought the water on foot while a few (12\%) used cycle. The remaining three per cent used rickshaw/tractor/motor cycle to fetch water. Many people reported that they had no choice but to go by foot as they couldn't afford to spend on petrol for scooters/ motor cycles just to procure water.

\section{Problems faced due to Scarcity of Water Supply}

An attempt was made to sum up the day-to-day difficulties faced by the SCs due to lack of adequate water supply.

Table 4. Problems Due to Scarcity of Water Supply.

\begin{tabular}{lll}
\hline Responses & $\begin{array}{l}\text { No. of } \\
\text { Respondents }\end{array}$ & Percent \\
\hline $\begin{array}{ll}\text { Compels the SCs to go to fetch } \\
\text { water from distant places which }\end{array}$ & 124 & 62 \\
$\begin{array}{l}\text { is time consuming and causes } \\
\text { physical discomfort }\end{array}$ & &
\end{tabular}


Scarcity of water leads to fights

120

and quarrels

Forces the poor to skip washing

100

clothes for days together/ keep

wearing dirty clothes

Compels the poor to skip bathing 75

for days

Dearth of water forces the SC

families to use alternative risky

water sources to take bath,

wash clothes e.g canal and

distributaries.

Forces the poor SC to drink

contaminated/ poor quality

water from alternate unsafe water

sources

Shortage of safe water leads to

illness and diseases

Inadequate water causes great

inconvenience as it compels them

to pick up the material and go to

alternative sites for bathing and

washing e.g. water works site

Dearth of water coerces the poor

SC to purchase water from tanker

supply/RO

Note: Total and percentage varies due to multiple responses

Source: CRRID Field Survey, 2017

Sixty two per cent households reported that due to inadequate supply of water, they had to fetch water from distant locations. This results in women and children carrying heavy buckets of water from distant places. It is not only time consuming but also caused physical discomfort. Scarcity of water leads to unnecessary waste of time and energy. Sixty per cent reported that dearth of water resulted in enmity and constant quarrels with neighbours (when they go to ask for water again and again) and at water source. It also resulted in quarrels within the family as to who will go to fetch water. They also faced a problem owing to the heavy rush at the water source, which more often than not, leads to quarrels/feuds. Fifty per cent had to postpone washing clothes for days together due to scarcity in water supply.38 per cent stated that they were forced to skip their baths. They were forced to remain without bathing, wearing dirty clothes for days together. Some of them remarked that they were compelled to pick up the material (clothes, bucket, mug, soap, brush etc.) and go to take bath and wash clothes at water work site, which was very inconvenient.
Twelve per cent stated that they are also being forced to take water from canal directly, although water is of poor quality. Also going to fetch water from the distributaries is risky. People are also forced to take bath and wash clothes along the canal side and distributaries. Since, there is shortage of water, 95 per cent households complained that they were forced to drink poor quality, contaminated ground water from submersible/handpumps. 83 per cent of them reported that they were vulnerable to diseases due to scarcity and inadequate supply of water. Five per cent reported that they were forced to buy water from the tanker. This water from tanker is not of good quality, neither could SC families afford it, yet, they had no choice but to buy, due to paucity of water.

\section{Do SCs Households Purify/Filter Water before Consumption?}

Inspite of being aware of the poor quality of ground water, none of the respondents boiled/ treated/purified water, although 70 per cent of them did store some water in Pitchers. Majority of them were busy in other household chores and some of them were daily wagers also, so they had neither time nor energy to boil or filter water. Another very pertinent reason reported was that they couldn't afford the cost of fuel (gas/wood) to boil so many litres of water every day. Thus, inspite of being conscious that the water was unsafe, they did not purify it due to lack of time, energy and money.

\section{Availability and Usage of Reverse Osmosis (RO) Water}

Punjab government claims that it is taking all possible measures to provide a RO system for the supply of safe drinking water in the affected areas.RO/ Defluoridation Plants are being installed to ensure availability of potable water for drinking and cooking purposes in the villages where: i. Existing canal based water works are located at the tail end of canal network, resulting in shortage of raw water for many days in a year. ii. Tube-well based sources contains: a) TDS/ Fluoride more than the desirable limit. b) Uranium/ others heavy metals also more than permissible limits. The public $\mathrm{RO}$ was available in all the ten selected villages, although it was functional in eight villages at the time of survey. CRRID field study revealed only nine households $(4.7 \%)$ were availing this facility of getting water from RO. In addition, only one per cent had the facility of $\mathrm{RO}$ at home.

Majority of the SC families reported non-affordability of RO charges (Rs. 90 per month) as the major reason for not availing RO facility. Non- accessibility of RO due to its distant location from SC habitations and limited timings 
leading to rush and quarrels were other deterrents in procuring $\mathrm{RO}$ water.

\section{Quality of Water}

Quality of water is a serious problem in Punjab. Water quality is defined as being free from substances, including microorganisms, chemicals, and other hazards that threaten a person's health. As per DWSS, Punjab, "The rapidly deteriorating water quality is leading to serious health problems. It is suspected that the presence of contaminants like uranium and heavy metals, coupled with pesticides, are the causes. Roughly 29 per cent of water supply schemes face water quality issues in Punjab."

As per the Ministry of Water Resources, GOI, 2014, the ground water occurring in the southern and south western parts comprising of Muktsar, Bathinda, Mansa Ferozepur, Sangrur and Moga districts is saline to highly saline and is not suitable for drinking uses. Also Fluoride having concentrations more than $1.5 \mathrm{mg} / \mathrm{l}$ have been reported from Bathinda, Ferozepur, Mansa and Patiala Districts of the State. Further, higher concentrations of Uranium have been reported from several places in Bathinda, Mansa, Faridkot, Ferozepur and Moga Districts. The highest Uranium concentration of $350.3 \pm 3.60 \mu \mathrm{g} / \mathrm{l}$ has been reported from tube well water at depth of 470 $\mathrm{ft}$ at village Mangiana, block Budhlada of Mansa district. Regarding the overall water quality scenario of the State, ground water quality problem is more severe in the district of Mansa and few other districts. Very high values of Arsenic have been detected in Mansa district. The sub soil water of Mansa, Bathinda, Faridkot and Mukstar belt is not fit for human consumption. However, as per the government, almost all villages in Mansa get safe drinking water supply from the waterworks, but not in summer when water level drops.

Recently, The Tribune dated $3^{\text {rd }}$ Nov, 2017 highlighted that the Centre Ground Water Board (CGWB) teamhad collected various water samples from Mansa district. "They had found that arsenal and fluoride contents were exceeding the limits fixed by the World Health Organisation, thus making water unfit for drinking". The table given below gives an abstract of water quality in Mansa as per DWSS.

Table 5. Abstract of Mansa District Water Quality Profile.

\begin{tabular}{|c|c|c|c|c|c|c|c|}
\hline \multicolumn{2}{|c|}{ No of Schemes } & \multirow{2}{*}{$\begin{array}{l}\text { No. of schemes } \\
\text { failed due to } \\
\text { Uranium and } \\
\text { Heavy Metals }\end{array}$} & \multirow{2}{*}{$\begin{array}{l}\text { No. of } \\
\text { habitations } \\
\text { failed due to } \\
\text { Uranium and } \\
\text { Heavy Metals }\end{array}$} & \multirow{2}{*}{$\begin{array}{l}\text { No. of } \\
\text { schemes failed } \\
\text { due to Basic } \\
\text { parameters }\end{array}$} & \multirow{2}{*}{$\begin{array}{l}\text { No of } \\
\text { habitations } \\
\text { failed } \\
\text { in basic } \\
\text { parameters }\end{array}$} & \multirow{2}{*}{$\begin{array}{l}\text { Total no. of } \\
\text { Habitations } \\
\text { failed } \\
(\mathrm{U}+\mathrm{HM}+\mathrm{BP})\end{array}$} & \multirow{2}{*}{$\begin{array}{l}\text { No. of } \\
\text { habitation } \\
\text { covered } \\
\text { under RO } \\
\text { plants } \\
\text { projects } \\
(1811 / 561)\end{array}$} \\
\hline $\begin{array}{l}\text { Tubewell } \\
+\mathrm{HP}\end{array}$ & Canal & & & & & & \\
\hline 20 & 140 & 8 & 10 & 4 & 8 & 18 & 16 \\
\hline
\end{tabular}

Source: Water Quality, DWSS, Punjab, 2017

It is evident that from 20 schemes of tubewell/hand pump and 140 from canal, 8 schemes failed due to Uranium and heavy metals and four failed due to basic parameters. All total, 18 habitations failed due to Uranium, heavy metals and basic parameters in Mansa. As per the detailed data provided by Water Quality, DWSS, Punjab, 2017, the water sample failed in a number of villages in block Bhiki due to the presence of heavy metals like Aluminium and Mercury and basic parameter like Fluoride beyond permissible limits. In Block Budhlada, the scheme in some villages failed due to parameters like Aluminium, Mercury and Uranium found beyond permissible limits. In Block Sardulgarh, aluminium was found beyond permissible limit in few villages among heavy metals and Fluoride among basic parameters.

The results of the CRRID survey revealed that except for piped water from water works reported by some households in a few villages as safe, 95 per cent of the households reported that the drinking water largely consumed by them was unsafe. Water was not available in adequate quantity and was not accessible to all. Therefore, due to paucity of water from water works, SC families were forced to drink water from alternative sources, and so a large majority reported that the drinking water consumed by them was not safe.

Almost all SC respondents in the survey reported that the water contained high proportion of toxic elements and heavy metals although most of them could not exactly identify them. Many of them reported that it had high proportions of Total Dissolved Solids (TDS), although as per DWSS data it is not beyond permissible limits. Majority highlighted that water was contaminated and not fit for consumption. The ground water contained high proportion of shora in water and water was khara in taste, was repeatedly stated by the respondents. Many infuriated that the quality of water in their village was very poor, even if it was piped water. The above mentioned information from secondary sources and the feedback from the SC families during the 
course of study further aroused the curiosity of the researcher to examine this quality aspect in detail:

\section{Eye-opening revelations regarding quality of water:}

Field survey brought out that canal water was of good quality but as already mentioned, there is almost always dearth of piped water supply, and so many SC families primarily relied on ground water (Handpumps/bore well/ submersible) which was highly contaminated and was not fit for drinking.Inspite of being aware about its poor quality, many times, SC families had to consume this ground water containing high proportion of aluminium, Shora, Uranium, and Fluoride. It was reported that water was often muddy, yellowish and smelly.

Further, the villagers accepted canal water was safe and even water from water works was pure but reported a lot of problems as to how even water from water works which is supposed to be clean, filtered and with addition of medicines also gets contaminated. In village Fatta Maluka, water for water works and borewell was checked and the sample failed when it was dug $300 \mathrm{ft}$. below. This was true of many other villages in Mansa also, the SC families expressed. In Aklian, the SC families expressed that the DWSS, Punjab itself has cautioned the villagers against the consumption of the water from water works as it is unsafe. In light of this feedback, an attempt was made to study the reasons from the villagers as to how safe water from the water works gets contaminated. The responses are as under:

- Majority of the water pipes are very old, never changed or repaired since a number of years by the Government/ Panchayat. In fact, in a few villages the water pipes have not been changed since last 40-50 years. So the drinking water pipes are full of cracks and are broken at several places. These cracked/ leaking pipes run along the kutcha road side along with which the open drains are flowing in villages. The drinking water which is carried in cracked/leaking pipes and open drains flow together, getting intermixed at several places resulting in water getting contaminated.

- The placement of pipes carrying water from water work was outside the houses which are above the open drains. Due to absence of sewerage; the open drains in the village are blocked and so are full with garbage, filth, slush and garbage. These drains overflow with filth in rains. In many houses the drains slush level goes higher than water work pipe/tap and hence there are chances of drinking water getting mixed with open drainage water and so it becomes unsafe and dirty.

- People keep meddling with the water work connections/ pipes located outside their house to pull water into their houses from outside as generally the pressure of water is low. They try to fit tullu pumps/pipes of different sizes/ valves etc. due to which many a times the plastic pipes/ or valves get cracked resulting in dirty water getting mixed with water from water works. Thus, villagers' fiddling with water pipes was another reason reported for contamination of water.

- In certain village, at the time of survey, it was confirmed by the Sarpanch that the filters in the water works were not functional as they were blocked since long and so water from water works was smelly and dirty. Thus, delays and postponement in repair work for a long period also forces villagers to think that water from water works is not safe but they have no choice than to consume it.

- During rains, the height of slush in open drains goes above the level of water works pipe in villages and so the dirtywater automatically mixes with drinking water contaminating it. Thus, drinking water becomes unsafe, when it reaches the houses.

- $\quad$ Lack of security, watch and maintenance contributed to the dirtying of water at the open water works. During the field survey, it was reported that dogs take bath in the open water works. There were incidents when buffaloes were fallen and died in water works, as they are uncovered and there was lack of monitoring. Gates were left open at times. Many insects and birds kept dying in the open water works and people had to consume this dirty water.

Although Government claims that canal water based supplies are safe, but the empirical study clearly revealed that canal water, which is supplied to several villages through local waterworks, remains unreliable. Thus, the critical challenges that SCs face is to secure an adequate source of water in terms of quantity and quality. Lack of water connections, poor access, scarcity of water, low water pressure, discrimination in access and poor quality of water were the major problems SC households face with regard to water. Further, the quality of safe water from water works is ruined due to small/worn out/ old leaking pipes, uncovered water works and open pipes which are outside the house and near the open drains.

\section{Water Quality and Its Effects on Human Health}

Safe water is a basic human right which plays an important role in protecting our health. On the other hand, poor water quality spreads disease, causes death and obstructs socioeconomic progress. As per the World Health Organization, about 80 per cent of all sickness and disease is due to lack of safe water and sanitation.

An attempt was made to study the impact of quality of water on the health of the poor SC in our study. The respondents were asked if they or their family members had faced any health problems due to drinking water during 
the last few years. The field data revealed that 82 per cent respondents or their family members had fallen prey to diseases due to poor quality of water consumed by them.

Table 6. Distribution of SC Households According to the Major Diseases Suffered By Them Due to Poor Quality of Drinking Water.

\begin{tabular}{lll}
\hline Type of health problems & No. of households & Percentage \\
\hline Cancer & 13 & 8.0 \\
$\begin{array}{l}\text { Kala Pilia/jaundice/ } \\
\text { hepatitis }\end{array}$ & 40 & 24.5 \\
Joint pains & 77 & 47.2 \\
$\begin{array}{l}\text { Dental/Teeth problem } \\
\text { Problems related to uric }\end{array}$ & 43 & 26.4 \\
acid/Kidney problems & 28 & 17.2 \\
$\begin{array}{l}\text { Stomach problems } \\
\text { Respiratory problems/Bad } \\
\text { throat(cough)/ asthma }\end{array}$ & 22 & 19.6 \\
$\begin{array}{l}\text { Hair fall/Greying of hair } \\
\text { Skin problems/Rashes/ }\end{array}$ & 22 & 13.5 \\
Allergies/Boils & 25 & 13.5 \\
Regular Fever & 40 & 15.3 \\
$\begin{array}{l}\text { Typhoid/Cholera/ } \\
\text { Diarrhoea }\end{array}$ & 32 & 24.5 \\
\hline
\end{tabular}

Note: Total does not add upto 100 per cent due to multiple responses

Source: CRRID Field Survey, 2017

The households surveyed reported multiple health problems/diseases due to poor quality of water. The major health problems reported were weakening of bones/ Joint pains(47\%), kala pilia/jaundice/hepatitis (25\%),dental problems (26\%), stomach/digestive problems $(20 \%)$, cancer $(8 \%)$, urinary/ uric acid/kidney problems (17\%),respiratory problems/asthma (14\%), hair fall/ premature greying of hair $(14 \%)$ and skin problems (15\%).Many families (25\%) reported members suffering from regular fever. Another 20 per cent households reported other water borne diseases like typhoid/cholera/diarrhoea. Poor water quality also has a severe effect on children. Many poor villagers with skin allergies and decayed teeth (a basic indicator of high fluoride content) were seen in the study area.

Literature too provides the role of unsafe water resulting in diseases. Water Aid, 2017, too brings out the health impacts of water. It highlights that dental fluorosis, skeletal and Non-Skeletal fluorosis are caused due to fluoride in water. Long term exposure to arsenic in drinking water can lead to increased risk of cancer, abdominal pain, diarrhoea and skin problems.Similar findings were reported in the survey conducted by Punjab State Planning Board (Singh, 2008), which reveals hepatitis, gastroenteritis, cancer, joint pain, skin disease, asthma etc. in parts of Punjab. DWSS, Punjab itself points out that "the sub soil water of Mansa, Bathinda, Faridkot and Mukstar belt is not fit for human consumption". Hindu (2012)reported that there is high incidence of cancer and other diseases in Punjab's Malwa belt over the last decade.Further, as per The Tribune dated Nov 3, 2017, in Mansa, the Arsenic and Fluoride contents in water were exceeding the limits fixed by the WHO, thus making the water unfit for drinking. Experts say excessive fluoride consumption could cause skeletal fluorosis, dental fluorosis etc.

\section{Conclusion and Suggestions}

Access to safe drinking water is not only an indicator of the socio-economic status of the household but is also vital for the health of its members. Fulfilment of the right to water entails water that is available, accessible and safe. In spite of huge progress and highest coverage of water in Punjab; the water sector in rural areas continues to face major challenges. The problem is more acute among SC households. For many SC families in rural areas of Mansa, there are threats to all three elements of an individual's right to water i.e. there was inadequate water availability, lack of access to water and potential danger to water quality, leading to a number of diseases. Thus, despite enormous programmes on drinking water, it is observed that access to safe drinking water remains a major challenge especially for the marginalized sections of society in Punjab. Availability of unsafe alternate water sources continues to remain the major blockade. Punjab has not been able to safeguard equal realization of the right to water for all. Upcoming programs in Punjab should take into account the problems the poor SC populations face in accessing the upgraded water supply.

In light of above, the following are some of the suggestions:

- Giving villages $24 \times 7$ water supply should be the priority of the government. So, 100 per cent coverage of all rural households to have good quality individual potable water supply has to be ensured. It is therefore pertinent to provide free household metered water connections to all. It is also significant to develop service levels in schemes to $70 \mathrm{lpcd}$ and transfer to communities for management.

- Ensure a well-functioning system to register and address complaints regarding water access, quality and quantity etc.

- It is imperative to curb wastage of rural drinking water. Provide regular and refresher training to members of GPs/VWSCs to reduce wastage and improve 
service quality. It is also important to sensitize the SC Community on the methods to curb water wastage.

- It is important to formulate a State-Level and district level Empowered Committee to monitor and control water quality problems and a deteriorating availability of supply of drinking water.

- To ensure the availability, quality and sustainability of domestic water supplies to SC households in villages it is important to check cracks and leakages in water, so it becomes pertinent that government repairs/replaces old and damaged pipes carrying water from water works.

- Addressing water quality issues through monitoring and mitigation is pertinent: Emphasis has to be laid on improving the monitoring network and seasonal evaluation of all water sources. An immediate action plan, without any delay, for any contamination observed, has to be provided. It is pertinent to establish well equipped laboratories with well trained staff. Both field testing kits for a broader picture and laboratory tests for more accurate results are important.

- It is pertinent to maintain water quality. To achieve this, the users and the communities at large, have to understand their responsibility and feel accountable to maintain hygiene near water sources. Emphasis should be on sensitising and mobilising through Information, Education and Communication (IEC) among the masses to improve the method of water collection and storage so as to avoid contamination while collection, storage and use. The feeling that the users too are responsible for maintaining the safety of water has to be instilled.

- There is a need to promote community based water quality monitoring and surveillance at the grass root level as mechanism to spot problems and solve water related problems.

- Emphasis has to be laid on the participatory approach for planning, implementation and monitoring with the involvement of multiple stakeholders(such as PRIs, NGOs and the wide community) and the participation of primary stakeholders like SCs (the would-be users) in the process of planning goals and strategies so that the water programme is user-friendly, need-based, effective and sustainable.

- $\quad$ Promote Inter-Departmental Coordination. Water and sanitation programmes cannot be operated in isolation from programmes in health and education. Improved co-ordination amidst ministries and departments would ensure effective implementation.

- Emphasis should be laid on maintenance of infrastructure. There should be stress on proper upkeep of rural water supplies by government/panchayat. It is equally important that the users also feel responsible and handle small repairs instead of depending totally on the government, if it is taking time. This calls for a change in their mind-set so that they share responsibility.

- Exploring simple, low-cost treatment technologies is imperative. Once contamination is detected in a water source, there is need for treatment. In case of rural areas, government might not take immediate action and modern water purification technologies might not be viable at times. So, instead of consuming unsafe water, simple and cost effective traditional methods of water purification (if verified) like cloth filtration, boiling, chlorination etc. can be encouraged.

- Since PRIs are being recognised as the nodal implementation agencies for water and sanitation, so sufficient emphasis should be laid on capacity building of PRIs. Training PRIs is also imperative to make decentralization become effective, both in terms of functions and resources and to encourage poor-friendly governance.

- Efforts should be made to identify and prepare a compendium of best practices including nondiscriminatory practices related to safe drinking water for encouraging and replicating them for poor SCs in other areas also.

\section{References}

Census of India (2011). Percentage of Scheduled Caste/ Scheduled Tribe Households to Total Households by Amenities and Assets, Punjab, Office of Registrar General and Census Commissioner, Government of India.

Census of India (2011). Tables on Houses, households Amenities and Assets for Scheduled Castes, India, series 1, Office of Registrar General and Census Commissioner, Government of India.

Census of India (2011). Population Totals, Paper 1, Series 4, Punjab, Office of Registrar General and Census Commissioner.

Government of India (2014). Water Quality Issues and Challenges in Punjab, Central Ground Water Board: Ministry of Water Resources, Government of India, March 2014

Hannah Johns (2012). Stigmatization of Dalits in Access to Water and Sanitation in India. It was submitted at the Human Rights Council in September 2012, NCDHR (http://www.ncdhr.org.in/key-activities/ Stigmatization $\% 20$ of\%20dalits $\% 20$ in $\% 20$ access $\% 20$ to\%20water\%20-\%20sanitation.pdf/view)

Kapur. D, Ramisetty. M and Barot. N (2016). "Formative Research to Develop Appropriate Participatory Approaches towards Water, Sanitation and Hygiene in Rural Area," 
Water Supply and Sanitation Collaborative Council (WSSCC), India Wash Forum.

Khurana I and Sen Romit (2009). Issues and approaches for drinking water quality in rural India: a background paper by Water Aid, available at (http://www. indiawaterportal. org/articles/issues-and-approachesdrinking-water-quality-rural-india-backgroundpaper-wateraid)

Singh B.P. (2008). In rural Punjab, drinking water is becoming a silent killer: study, live mint-e-paper at http://www.livemint.com/.../In-rural-Punjabdrinking-water-is-becoming-a-silent-killer.html

SoniJasyhree (2006). Water Accessibility and Marginalisation of Dalits: Some Observation of Rural Gujarat, Centre for Social Studies (CSS), Paper prepared for the workshop entitled 'Water, Law and the Commons,' Delhi from 8 to 10 December 2006 by the International Environmental Law Research Centre (IELRC).
Swaminathan M and Singh S (2004). Deprivation among Dalits remains high (www.thehindu.com/ news/national/Deprivation-among-Dalits.../ article15511765.ece)

United Nations Information Service (2001). "Access to safe water fundamental human need, basic human right, says Secretary-General in Message on World Water Day" (March 13, 2001), available at http://www.unis. unvienna.org/unis/pressrels/2001/sgsm7738.html.

Water Aid India (2017). Drinking Water Quality in India, available at http://wateraidindia.in/wp-content/ uploads/2017/11/State-of-Drinking-Water-Quality. pdf

World Health Organization (2001). Water for Health, taking Charge, Geneva available at http://who.int/ water_sanitation_health/wwdreport1.pdf 